\title{
Oncology research in late twentieth century and turn of the century Portugal: a scientometric approach to its institutional and semantic dimensions
}

\author{
Oriana Rainho Brás ${ }^{1,2}{ }_{(D)} \cdot$ Jean-Philippe Cointet $^{3}\left(\right.$ Alberto Cambrosio $^{4}$ AD $^{\cdot}$ \\ Leonor David $^{2,5,6,7}$ ( João Arriscado Nunes ${ }^{8,9}$ (DD - Fátima Cardoso ${ }^{2,10}$. \\ Carmen Jerónimo ${ }^{2,11,12}$ (i)
}

Received: 20 February 2017

(C) Akadémiai Kiadó, Budapest, Hungary 2017

\begin{abstract}
This paper analyses the developmental dynamics of oncology research in Portugal during the second half of the twentieth century and early twenty first century. Grounding its conclusions in a scientometric analysis of a database of publications covering the period 1976-2015, the paper shows how the expansion of oncology research from the end of the 1990s through the 2000s is closely related to science and technology
\end{abstract}

Electronic supplementary material The online version of this article (doi:10.1007/s11192-017-2491-y) contains supplementary material, which is available to authorized users.

Oriana Rainho Brás

orianarb@socius.iseg.ulisboa.pt

1 SOCIUS-Research Centre in Economic and Organizational Sociology, CSG-Consortium of Social Sciences and Management, ISEG-School of Economics and Management, University of Lisbon, Rua Miguel Lupi, 20, 1249-078 Lisbon, Portugal

2 ASPIC-Portuguese Association for Cancer Research, Rua Júlio Amaral Carvalho, 45, 4200-135 Porto, Portugal

3 LISIS-Laboratoire Interdisciplinaire Sciences Innovations Sociétés, INRA-Institut National de la Recherche Agronomique, 5 Boulevard Descartes, Champs sur Marne, 77454 Marne-la-Vallée, France

4 Department of Social Studies of Medicine, McGill University, Peel St., Montreal, QC 3647, Canada

5 IPATIMUP-Institute of Molecular Pathology and Immunology of the University of Porto, Rua Júlio Amaral de Carvalho, 45, 4200-135 Porto, Portugal

6 Medical Faculty, University of Porto, Alameda Prof. Hernâni Monteiro, 4200-319 Porto, Portugal

7 i3S-Instituto de Investigação e Inovação em Saúde, Universidade do Porto, Rua Alfredo Allen, 208, 4200-135 Porto, Portugal

8 CES Centre for Social Studies, University of Coimbra, Colégio São Jerónimo, 3000-995 Coimbra, Portugal

9 Faculty of Economics, University of Coimbra, Avenida Dias da Silva, 165, 3004-512 Coimbra, Portugal 
policy decisions in the country. The main actors of the institutional evolution of the field are public organizations, both hospital and academia/research-based, frequently working together. Portuguese oncology research focused especially on organ-based cancers, underlining the strong link between the laboratory and the clinic. Accordingly, translational research is a major trend in oncology research, as evidenced by the analysis of publications in major journals and inter-citation maps. Networks of institutional coauthorships show the importance of regional and international collaborations. The collaboration patterns over time reveal the importance of national and European collaborations during the initial years covered by our publication database, in line with the major impact of Portugal's integration into the European Union, and a growing importance of regional collaborations, as well as with North and South American institutions in more recent years. Portugal provides a case study of how twentieth century policies at the national and European levels have impacted on the evolution of oncology research in countries from southern Europe.

Keywords Oncology research · Institutional collaboration networks · Semantic networks $\cdot$ Portugal $\cdot$ Scientometrics

\section{Introduction}

Scholars have analyzed the developmental dynamics-both organizational and epistemic — of oncology research at the international level (e.g. Keating and Cambrosio 2012), and at the national level, for a few large countries such as the US, the UK, and France. In contrast, we know little about the development of oncology in smaller countries, such as Portugal, in spite of the presence of a rapidly expanding local oncology research community and of the relevance of the cancer burden in the country. In Portugal, malignant neoplasms are the diseases with the greatest impact on morbidity, disability and premature death (Simões et al. 2017). They are responsible for $18.5 \%$ of total DALY (disability adjusted life years). Despite a decline in their standardized death rate, from a 164.5 per 100.000 inhabitants in 1995 to 152.0 in 2014, they were the leading causes of death in the country in 2014 (idem). With a few exceptions (Nunes 2001), most of the contributions devoted to the analysis of the development of Portuguese oncology focus on the first half of the twentieth century (Raposo 2004; Costa 2010, 2012a, b). As a result, we lack information about recent trends in Portuguese oncology research, and its relation to international research.

Our study aims at filling this gap by focusing on the development of oncology research in Portugal in the second half of the twentieth century and early twenty first century. Beyond the specific case of Portugal, our analysis provides indications of how twentieth century science and technology policies at the national and European levels might have impacted the evolution of oncology research in semi-peripheral Southern European

\footnotetext{
10 Champalimaud Foundation, Avenida Brasília, 1400-038 Lisbon, Portugal

11 Portuguese Oncology Institute of Porto (IPO Porto), Rua Dr. António Bernardino de Almeida, 4200-072 Porto, Portugal

12 ICBAS UP-Institute of Biomedical Sciences Abel Salazar, University of Porto, Rua de Jorge Viterbo Ferreira, 228, 4050-313 Porto, Portugal
} 
countries. We base our conclusions on a scientometric analysis of Portuguese oncology publications encompassing the period 1976-2015. We first approach the data by relating the growth in the number of publications to changes in the research policy context. We then look at the institutional evolution of the oncology field, by identifying the main oncology research organizations in the country, and characterizing their activities and collaborative patterns as made visible by publication co-authorships. Finally, we further characterize the field by text-mining publications in order to identify the main research topics.

\section{Methods and data}

To explore the development of oncology research in Portugal from the second half of the twentieth century we adopted a social studies of science perspective in combination with a scientometric approach. Bibliometric and scientometric methods are an increasingly common way to analyze scientific publications as important sources of information on scientific and clinical work. Although publications are our main data source, we do not confine ourselves to the usual bibliometric parameters; rather, we also explore the ecology of institutions involved in scientific research and their collective activities. As shown by recent developments in translational research, oncology is a multidisciplinary, extremely dynamic field with no pre-set boundaries. In addition to clinical oncologists, it involves a growing number of other specialists such as pathologists, biostatisticians, biologists, and researchers in domains such as molecular oncology and cancer genomics. Furthermore, oncology cannot be reduced to its human practitioners, but can be understood as a bioclinical collective that links researchers and clinicians to entities such as research tools, biological pathways, pathogenic phenomena, and new clinical techniques. To study these features, we resorted to the software platform CorText (http://www.cortext.net/) developed by IFRIS (Institut Francilien Recherche, Innovation, Société). CorText allows for the numerical analysis of different kinds of scientific outputs and, most importantly, for the distributional and relational analysis of different types of agents (human and non-human) that characterize a given domain of scientific activities at a given time (CorText 2012). To create a database of Portuguese oncology publications we queried in parallel the databases Web of Science (WoS) of Clarivate Analytics and Medline/PubMed of the U.S. National Library of Medicine. We searched the WoS for publications with "Oncology" as the subject, whose authors were affiliated with Portuguese institutions. Similarly, we searched PubMed for publications that were indexed with the MeSH descriptor "Neoplasms" (which captures a large number of children descriptors, such as cancer or tumour; see Grassano et al. 2016) and whose authors had Portuguese affiliations. ${ }^{1}$ Given that Medline/ PubMed does not include information about cited references, we used the PubMed ID to retrieve from WoS the publications identified in PubMed. These combined queries retrieved 5725 publications covering the 1976-2015 period. The database features different types of publications, including journal articles, meeting abstracts, review articles, editorials, proceedings papers, etc. For each publication, we retrieved the most relevant information including title, abstract, keywords, journal, date, volume, pages, authors and coauthors, their institutional affiliation, cited references, DOI, document type, and funding.

\footnotetext{
1 The database therefore includes the research conducted in Portuguese institutions regardless of the nationality of the researchers.
} 
Until 2014, Medline/PubMed (contrary to WoS that listed the affiliation of all coauthors) only included the affiliation and address of the first author. Therefore, publications not listed as Portuguese in PubMed (either because Portuguese co-authors were not first authors or because PubMed did not list any authors' affiliations and addresses), and which, additionally, were not retrieved solely through the WoS query, were not included in our database. Also, major databases such as Medline/PubMed and WoS do not include publications in local journals from peripheral countries, that may nonetheless be considered relevant for our present purpose (Ràfols and Molas-Gallart 2016). Indeed, it is to be expected that, until the end of the 1990s, a share of Portuguese articles was published in journals not indexed in either WoS or PubMed. ${ }^{2}$ We are thus aware that the database is not exhaustive. However, our aim was to capture collective patterns at higher level of aggregations and not to evaluate the performance of specific actors.

The analysis of institutional affiliations presented specific challenges that deserve mention. First, we had to standardize the name of each research institution. Not only did authors spell the name of their institution differently (e.g., using a Portuguese or English version of the name, or different abbreviations), but frequently the same institution changed its name during the period covered by our database, in which case we used its current denomination.

The second, even more serious challenge emerged when a first basic analysis of institutional affiliations showed a predominance of universities and a relatively small presence of associated laboratories, ${ }^{3}$ in spite of the fact that at least some of these laboratories were known to be major players in oncology research. This turned out to be an artefact of the parsing algorithm, which, in the case of multiple affiliations, only extracted the affiliation most closely associated with the geographical location, which turned out to be the university rather than the laboratories. To correct the situation, we identified all associated laboratories working in the field of oncology in Portugal, and re-indexed the articles by creating a new field that could be correctly parsed by CorText. As a result, and as discussed below, most associated laboratories were now correctly identified among the large producers of research outputs.

\section{Oncology research in Portugal in the second half of the twentieth century}

\section{Publications}

The growth in the number of publications in our database correlates closely with the evolution of public science and technology policies in Portugal (Fig. 1). Until 1994, a period during which public investments in science and technology were quite limited, Portuguese oncologists published less than 50 articles per year. While initial attempts to establish a science and technology policy, influenced by the role played by the Organization for Economic Cooperation and Development (OECD), can be traced back to the 1960s, the creation in 1967 of JNICT_Junta Nacional de Investigação Científica e Tecnológica ${ }^{4}$ did not lead to significant results (Gonçalves 1996). In particular, the budget for science and technology

\footnotetext{
2 Of the top 100 journals in our database two are Portuguese: Acta Medica Port $\left(11^{\circ}\right)$, Rev Port Cardiol $\left(32^{\circ}\right)$. In $27^{\circ}$ place there is the Brazilian journal An Bras Dermatol. Thus, in our top 100 journals we retrieved three in which publications may have been mostly written in Portuguese language.

3 See below for a definition of associated laboratories.

4 National Committee for Scientific and Technological Research.
} 


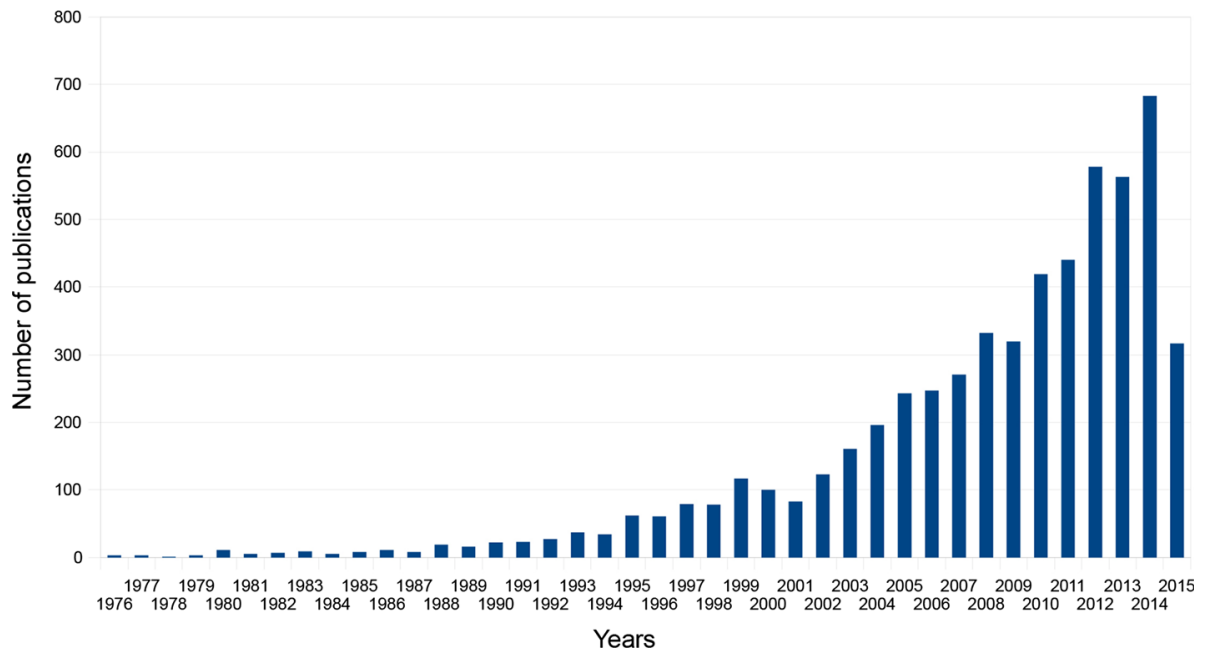

Fig. 1 Number of publications over time 1976-2015

remained largely inadequate (Heitor et al. 2014). The democratic constitution of 1976coincidentally the year of the first publications in our database-referred to the State's responsibility to promote science and technology to support the country's development (Gonçalves 1996). In the second half of the 80s, with Portugal joining the European Union in 1986, the government, spurred by the OECD recommendations and by pressures from Portuguese researchers to place science and technology on the agenda, launched an institutional reform and promised to increase public investment in research and development (Gonçalves 1996). In the following years, governmental activity in the research domain focused mainly on obtaining additional European funding rather than designing and promoting innovative science policies (Gonçalves 1996). In the beginning of the nineties, the program CIENCIA, co-funded by the Portuguese state and the European Union, was the main source of funding for research in Portugal (Gonçalves 1996). By this time, with the support of European Structural Funds, JNICT implemented programs supporting individual research fellowships and physical infrastructures (Heitor et al. 2014). This resulted, among other things, in a modest increase in oncology publications through the 1980s and during the 1990 s, followed by a period of very rapid growth beginning in the late 1990s and early 2000s. ${ }^{5}$ A similar trend was visible throughout all scientific fields in Portugal (Pordata 2016). This period of rapid growth was most certainly related to the creation, in 1995, of the Ministry of Science and Technology and, in 1997, of the Foundation for Science and Technology within the Ministry of Science. The Foundation was responsible for promoting and supporting, evaluating and funding scientific research. Thus, by the end of the 1990s the basis for a new science and technology system in Portugal was established. It included the international assessment of research units and the award of ten-year contracts to large research centres called "associated laboratories", which were created in 2000 (Heitor et al. 2014). The public funding for university-based research units increased very significantly from 1995 to 2002 reaching its highest value in 2005 (Heitor et al. 2014). The European Union and its funding policies were instrumental in promoting the creation of these

\footnotetext{
5 The apparently striking reduction from 2014 to 2015 is misleading since the database was built in October 2015 leaving out a considerable number of publications coming out in the last months of 2015.
} 


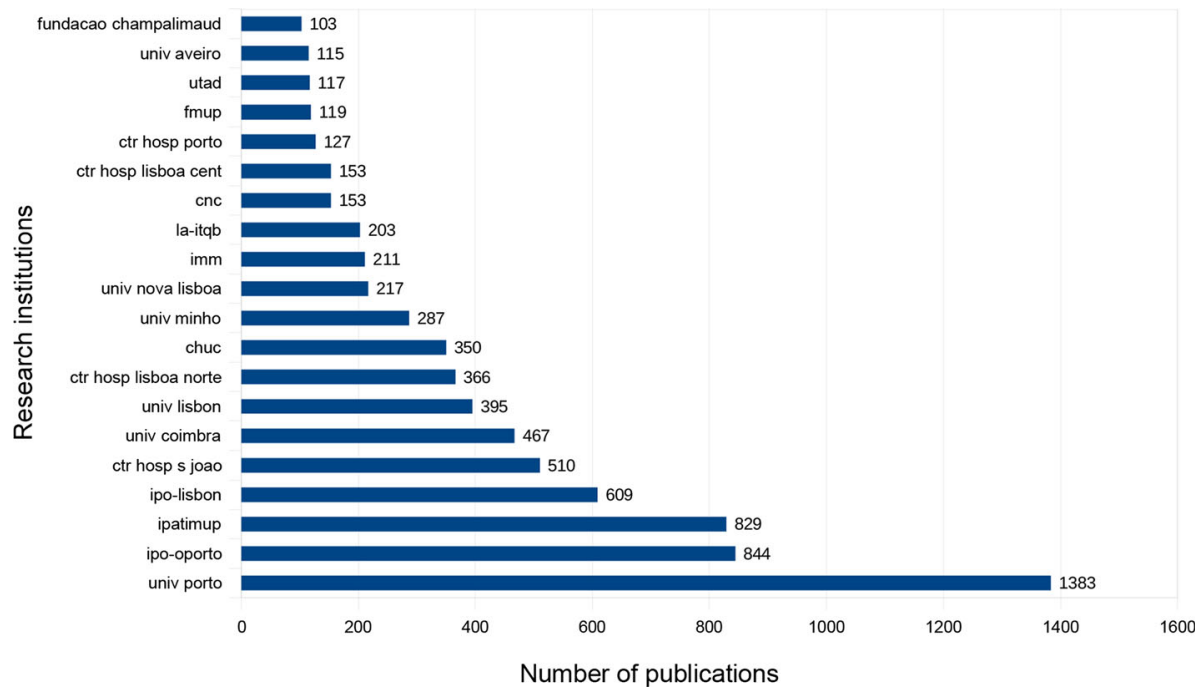

Fig. 2 Number of publications of the top 20 research institutions

associated laboratories that enjoyed a large degree of autonomy, received direct funding from the state, and were able to hire researchers directly. Significantly, some of these laboratories were involved in oncology research. (See online resource 1 for a brief chronology of science and technology policies in Portugal in the twentieth century)

The growth in the number of publications can also be related to the decisions of the Lisbon European Council in 2000, which prompted Member States to increase funding and productivity in research and development (Eckhouse and Sullivan 2006). While Eckhouse et al. (2005) argue that their actual impact in the oncology field was rather limited, they also note that surveys in 2002-2003 and 2004-2005 showed a significant increase in governmental and philanthropic funding for oncology research in the European Union.

\section{Institutions}

In this section, we discuss the institutional landscape of oncology research in Portugal. Cancer research takes place in a number of different institutions: specialized oncology hospitals (IPOs) but also general hospitals, universities and research institutes. Our results, however, show a significant concentration of publications in a relatively small number of institutions (Fig. 2).

The highest-ranking institution-University of Porto-(co)-authored $24 \%$ of all publications, ${ }^{6}$ while the twentieth institution (co)-authored $2 \% .^{7}$ The three top publishing institutions are from the city of Porto, but the top twenty research institutions represent all regions of the country, except the south and the central inland. The top-ranking institutions, however, are located in three cities-Porto, Lisbon, and Coimbra—-that host the oldest universities in

\footnotetext{
6 The publications of institutions do not add up to the total number of publications in the database because each publication is frequently co-authored by more than one institution.

7 We computed all the institutions authoring the publications and not just the Portuguese ones. From the twenty first institution onwards an increasing number of foreign institutions appear in the ranking.
} 
the country and the major hospitals. The top twenty institutions have very different ages, some being relatively recent, and thus their direct comparison would be misleading.

Seven of the top twenty institutions are hospitals or care providing institutions-university, general hospitals, or specialized oncology hospitals - which means that a considerable share of Portuguese oncology research is produced within clinical settings (which does not imply it is solely clinical research). Types of publications differ between clinical and non-clinical settings (universities, research centers and associate laboratories). Among the top twenty research institutions, hospitals published a higher proportion of meeting abstracts, with only one exception, the Hospital Centre of Porto, whereas publications of universities and associated laboratories consisted of more than $60 \%$ articles.

Different publication types point to different kinds of research and reward systems in clinical vs. non-clinical research. A majority of publications in our database $(57 \%)$ are articles, with a relatively large presence of meeting abstracts $(27 \%)$, followed by reviews $(7 \%)$, editorial material (3\%), letters and proceedings (2\%), and other types of publications (less than $1 \%){ }^{8}$ We observe a general increase in editorial material and reviews, possibly indicating a growing visibility of oncologists working in Portugal, since this type of publications are frequently made upon a journal's invitation. Other factors related to the growth of editorials and reviews may include the presence of Portuguese researchers in editorial boards and international research associations, but also, in the case of reviews, financial cuts in research producing novel results, redirecting publication activities. The highest proportion of reviews is to be found in three institutions-Champalimaud Foundation, the CNC-Center for Neurosciences and Cell Biology and the IMM-Institute for Molecular Medicine- that are also characterized by a high degree of thematic specialization, which may explain why their researchers have become authoritative speakers on those topics and have therefore been increasingly invited to review them.

If we now look at the evolution of the number of publications by research institution, we notice three distinct growth periods, which can be related to political developments in the country.

The creation of the Portuguese Oncology Institute (IPO) in Lisbon in 1923 is related to several societal, medical and political movements that led to its establishment as the official center for oncology in the country (Raposo 2004), with a clear mission to focus on research as an activity at least as important as care (IPO 2016). The IPO regional centers in Coimbra and Porto were created by the government only much later, i.e. in 1967 and 1974, respectively. This historical fact accounts for the prominent role of IPO Lisbon in the two first decades of our database. A second period, beginning in the 1990s, is associated to the aforementioned profound changes in the Portuguese science and technology system, namely the advent of a democratic regime and Portugal joining the European Union, which resulted in the design and consolidation of a public policy for science and technology and, in particular, in the creation of oncology research units and laboratories. Beginning in 2000, the University of Porto played a leading role in these developments, together with IPO Porto and Ipatimup (Institute of Molecular Pathology and Immunology of the University of Porto). Finally, a third period beginning around 2005 was characterized by a marked expansion in the number of research centers ${ }^{9}$ and their funding, as well as an increase in the number and diversity of university departments and research units dedicated to oncology.

\footnotetext{
${ }^{8}$ For greater clarity in reading and interpreting data, we aggregated some of the original categories for types of publications. We aggregated the original categories "Article proceedings paper" and "Proceedings paper" into the category "Proceedings", and we aggregated the original categories "Note", "Review book chapter", and "article book chapter" into the category "Other".

9 Some of which figure in the top 20 institutions, demonstrating a rapid growth in their production.
} 


\section{Institutional collaboration}

Co-authorship analysis provides a possible metrics for measuring and understanding institutional collaborations as key components of the organizational dynamics of oncology research. In the case of clinical research, collaboration between institutions and between countries became unavoidable due to the evolution of oncology, and the molecular biology-based re-classification of tumors that led to a fragmentation of patient populations. Clinical trials ran by a single institution, for example, are quite rare. Most trials are multicentric and very often multi-national.

\section{$1976-2015$}

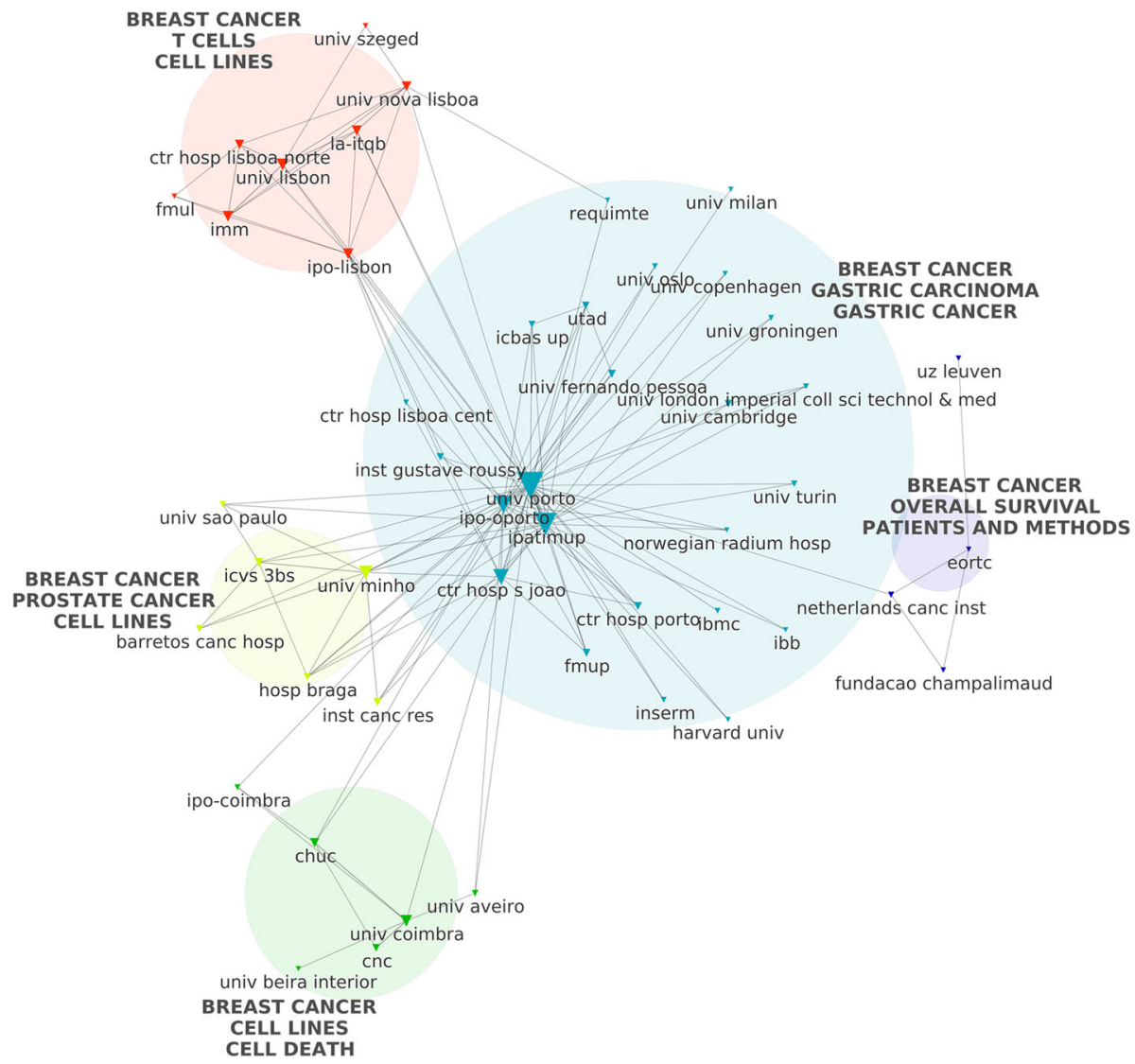

Fig. 3 Network of institutional collaboration with more frequent terms, 1976-2015 (raw proximity measure). To read this figure (and the following ones of the same kind) we should notice that each node represents one institution and its size is proportional to the number of co-occurrences (co-authorships) it features in the database. Each node's colour identifies a different cluster. The more institutions co-occur the closer they are in the figure, thus forming clusters and the connections between them. We tagged the network with the more frequent terms in each cluster thus identifying the main themes of the collaborations. The network represents the raw number of collaborations between the top fifty institutions using an optimal distance threshold 
We therefore produced a map of the collaboration network by analyzing the publications co-signed by authors from the top fifty research institutions. We then identified the main topics of these collaborations by labeling each resulting cluster with the more frequent terms extracted from the corresponding articles.

Figure 3 shows a star-like network consisting of a central cluster centered on three major institutions, surrounded by four other clusters connected to the central cluster but not among themselves. All clusters have a regional character corresponding to the following geographic locations: Porto, Lisbon, Minho, the center of Portugal, and, lastly, a cluster with a single Portuguese institution, Lisbon-based Champalimaud Foundation. With one exception (the center of Portugal cluster), all clusters feature collaborations with foreign research institutions.

Breast cancer is central to all collaborations, and is the more frequent term in all clusters. Other themes relevant for collaboration are cell lines, T-cells, gastric cancer, overall survival, patients and methods, prostate cancer, and cell death. As we will see below, this thematic landscape is quite different from the general thematic network of Portuguese oncology, which means that collaborations focus on only a subset of specific topics.

To analyze the temporal evolution of institutional collaborations we examined their transformation during four different periods (1976-1999, 2000-2004, 2005-2009, 2010-2015) (Fig. 4). The first period covers publications in our database from the initial ones in 1976 until the beginning of rapid growth in publications in 1999.

Figure 4 shows both recent and longstanding institutional collaborations. While initially international collaborations were mostly confined to European institutions, more recently we see the emergence of collaborations with the USA, Brazil and Canada, a pattern that can be related to the development of science and technology following the admittance of Portugal to the European Union.

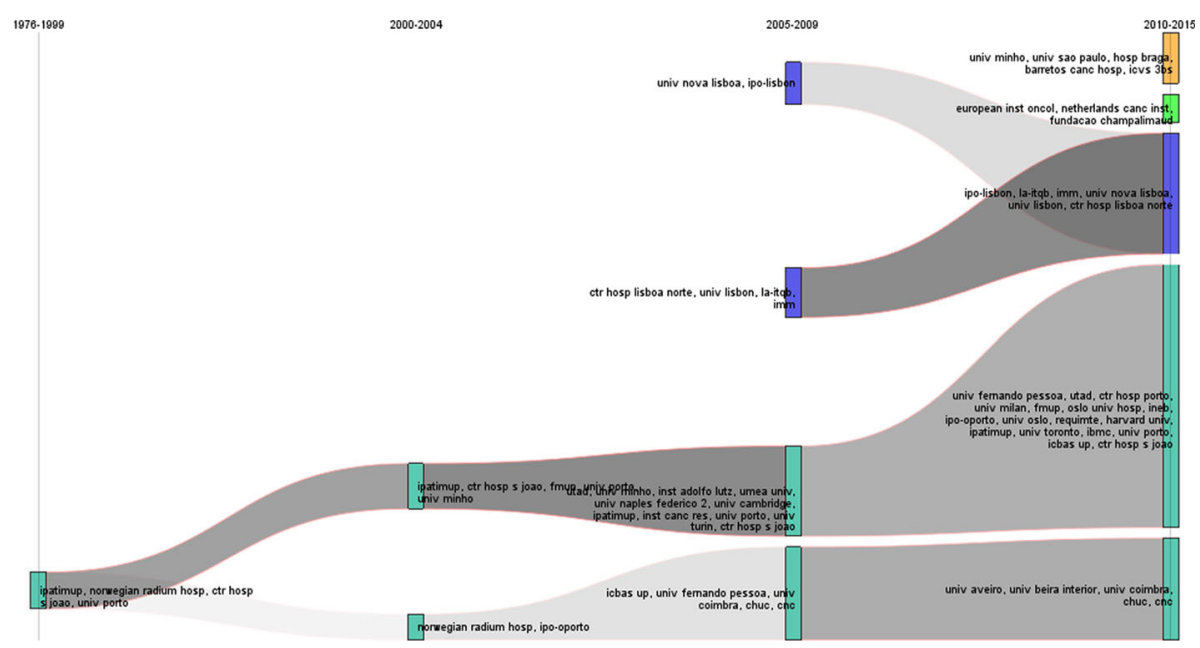

Fig. 4 Networks of institutional collaboration over time (raw proximity measure). The width of tubes is proportional to the number of records, i.e., the wider tubes represent clusters of institutions with a large number of co-authored publications. Also, darker tubes are more robust, i.e., they represent clusters which share more nodes between two consecutive time periods 
The more recent periods feature clusters corresponding to recent institutions, the Champalimaud Foundation (created in 2005), and Minho's institutions: ICVS (created in 2003) and the University of Minho (founded in 1973). Another cluster results from the convergence of two previous clusters of Lisbon-based institutions. The other clusters correspond to longstanding collaborations: one consists of institutions from Porto subsequently joined by organizations from the northern region of Portugal and foreign institutions; the other, smaller one, consists of IPO Porto and the Norwegian Radium Hospital, later joined by institutions from Coimbra.

Figure 5 shows a map of specific collaborations for the top fifty research institutions. As contrasted with the absolute number of co-authorships between institutions, maps featuring specific collaborations take into account the relative importance of co-authorships. They

\section{$1976-2015$}

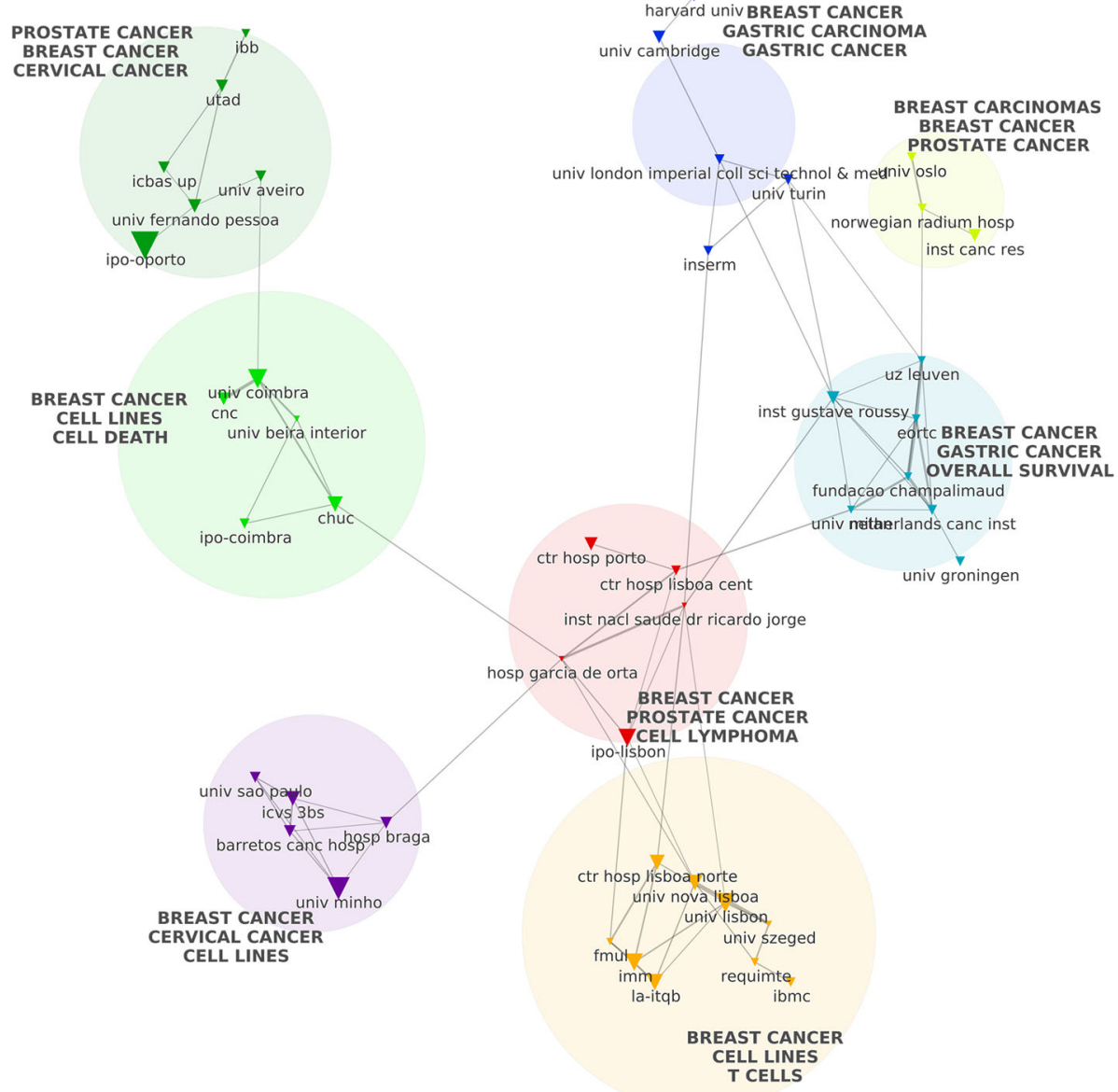

Fig. 5 Network of specific institutional collaboration with more frequent terms, 1976-2015 (Cramer proximity measure). The network represents only the specific collaborations between the top fifty institutions using an optimal distance threshold 
privilege the statistically surprising links between institutions, i.e. those that occupy a greater proportion of the total number of collaborative links. These "specificity" maps provide us with information about strategic aspects of the programs adopted by Portuguese oncology organizations. We can, for instance, investigate whether some institutions have opted for regional collaborations while others have favored foreign collaborations, or adopted a balanced approach. We can subsequently try to account for these strategic choices.

Let us first note that the University of Porto and Ipatimup, the two major institutions on Fig. 3 in terms of the absolute number of co-authorships, do not appear on the specificity map (Fig. 5), a pattern that indicates that they collaborate more or less equally with all other institutions, which is consistent with their central role in the collaboration network. Figure 5 further shows that most Portuguese institutions maintain strategic collaborations at the national level. Recent institutions (e.g., the Champalimaud Foundation) or those recently devoted to oncology research (e.g., the University of Minho) appear to privilege international collaborations. They have also established specific collaborative ties with extra-European institutions, which may be an indicator of novel patterns of international collaboration, due either to recent shifts in research focuses (e.g., the emergence of new topics and technologies) and/or related shifts in the circulation of researchers within the international oncology community.

A map of the evolution of specific collaborations (Fig. 6) shows that while a strong European presence characterizes international collaborations during all periods, this is particularly the case for the first period, as international co-authorships in all clusters consist mainly of linkages with European institutions. This confirms that international collaborations, in particular with European institutions, played an important role in the initial development of Portuguese oncology research. However, the four larger clusters of the most recent period include only national co-authorships. This could either mean that Portuguese institutions have increasingly privileged national collaborations in recent years, or that they have diversified their international collaborative ties to a point where none of them occupies a special place. A comparison with the absolute number of co-authorships provides evidence favoring the first hypothesis. At this point, however, we do not have sufficient data to account for the reasons that have led to a partial decrease in the relevance of international collaborations.

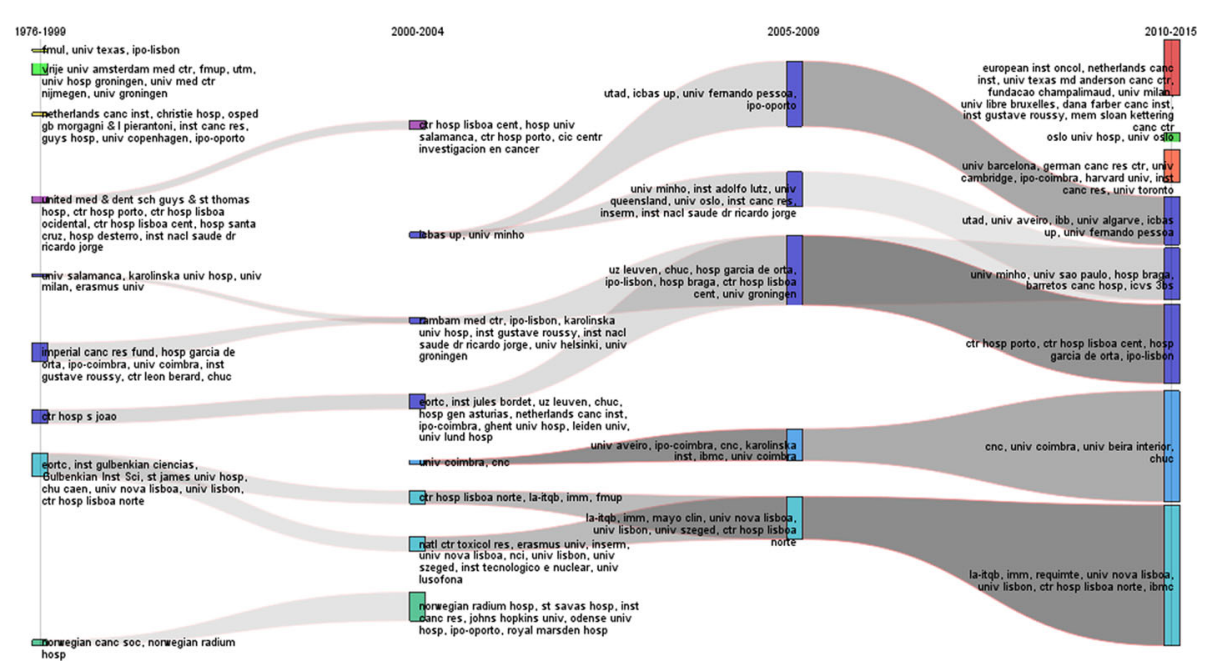

Fig. 6 Networks of specific institutional collaboration over time (Cramer proximity measure) 
$1976-2015$

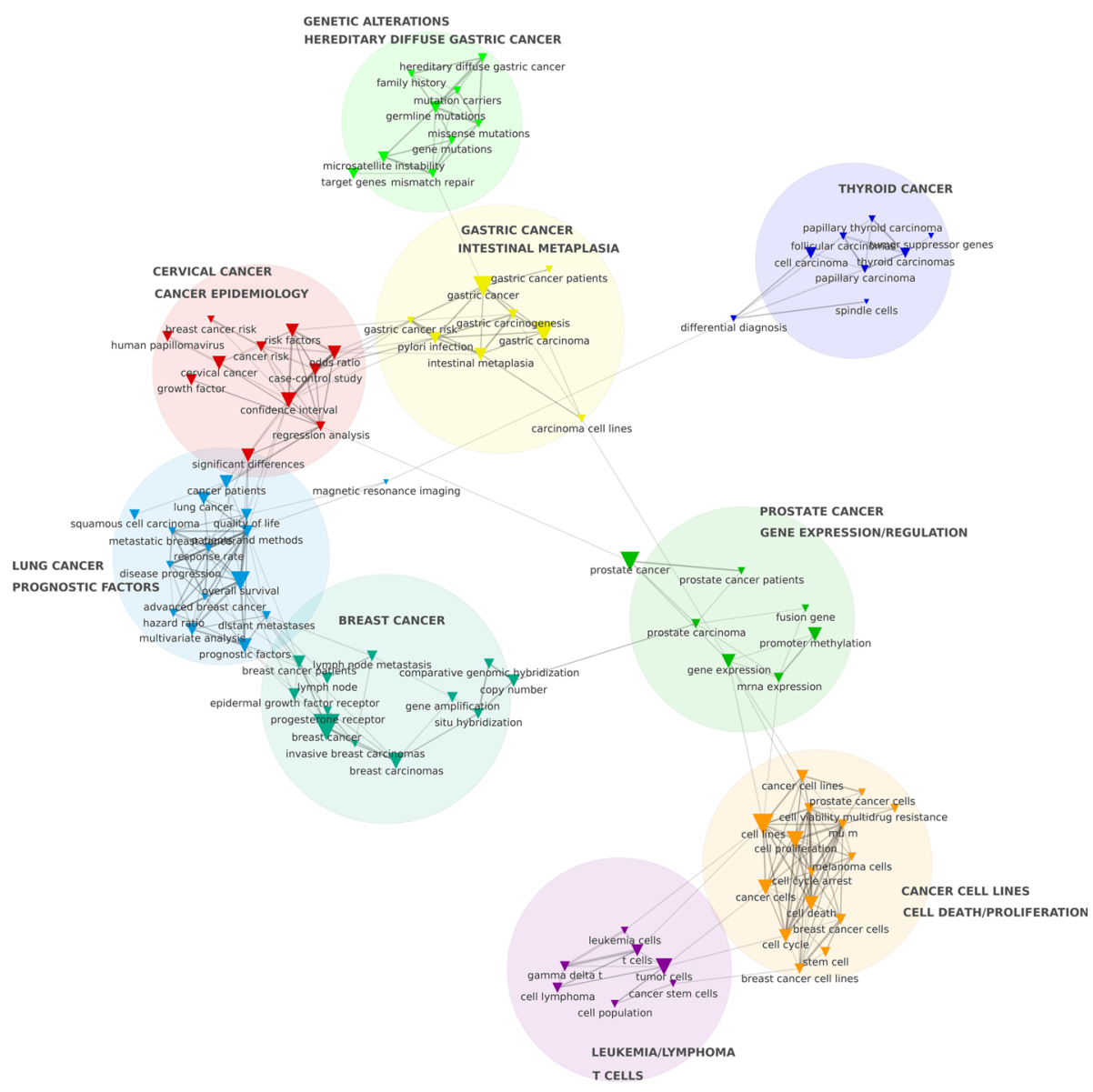

Fig. 7 Semantic network of the period 1976-2015. In this figure, each node represents a term and its size is proportional to the number of co-occurrences it features in the database. Each node's colour identifies a different cluster. The more terms co-occur the closer they are in the figure, thus forming clusters and the connections between them. We tagged the clusters according to the more frequent and relevant terms in each. CorText also suggests tags for the clusters, based in term frequency or in term proximity. Our naming of the clusters was highly coincident with either of CorText tags. To build this network we used a threshold to map the more relevant co-occurrences without loss of information

\section{Thematics}

After investigating the presence of institutional collaborations, we proceed to the analysis of the content of those collaborations. To this end, we used the Natural Language Processing tools provided by the CorText platform to identify the terms occurring in titles, abstracts and keywords of the publications in our database. We extracted 98 terms and analyzed their distributional co-occurrences. The resulting semantic network (Fig. 7) shows the main themes in Portuguese oncology research from 1976 to 2015.

Figure 7 features nine main thematic clusters, strongly focused on organ-centered research (stomach, intestine, thyroid, uterus, lung, breast, prostate, and 
leukemia/lymphoma). This is hardly surprising, given the strong links of Portuguese oncology research to pathology and clinical work and, in particular, the fact that a large amount of research publications has been triggered by physicians who share an interest in research. Historically, in Portugal, oncology research emerged in very close connection to clinical practice. To perform research and provide specialized cancer care to the general population was the guiding principle underlying the creation of the three IPO, especially the one from Lisbon. As previously mentioned, the profile of the research institutions doing oncology research in Portugal presents a balance between non-clinical and clinical institutions. Significantly, most clusters featured on maps of collaborative institutional networks include both kinds of institutions. This signals the relevance of translational research, that is, research based on the "exchange of concepts and techniques between fundamental biology and medical practice" (Cambrosio et al. 2006: 3140).

To further investigate these patterns, we analyzed the research level of the top twenty journals $^{10}$ in our database (which account for nearly $20 \%$ of the publications in the database), using Lewison and Paraje (2004) metrics. ${ }^{11}$ According to these calculations (see Online Resource 2) $40 \%$ of those publications are in clinical investigation journals and $38 \%$ in clinical observation journals. ${ }^{12}$ In contrast, $43 \%$ of the publications in the top twenty journals cited by Portuguese articles (see Online Resource 3) are in basic research journals, while $25 \%$ are in clinical observation journals. ${ }^{13}$ We additionally analyzed intercitation patterns (Cambrosio et al. 2006; Jones et al. 2011) by producing maps of the intercitation network linking citing and cited journals for two periods (2000-2005 and 2010-2015). The inter-citation network for the 2010-2015 period (data not shown) features a clinical pole and a basic research pole consisting of two main subdomains: molecular biology and pharmacology/biochemistry. These two poles are connected by two translational interfaces, one that centers on hematology-oncology, includes clinical mix and clinical investigation journals, and thus appears to be closer to the clinical pole, and a second one that contains journals that publish laboratory research articles and is thus closer to the basic pole. The inter-citation pattern for the 2000-2005 (see Online Resource 4) period is similar but by 2010-2015 (data not shown) an additional number of translational journals appear to have infiltrated the clinical and basic research poles, thus pointing to the increasingly hybrid nature of these different kinds of activities.

Maps only provide initial insights into the research dynamics, pointing to issues and questions that deserve more detailed, qualitative investigations. An example is provided by gastric cancer that figures prominently on our thematic maps. Nunes (2001), in his ethnographic analysis of gastric cancer research in the 90s in a Portuguese laboratory, has shown how Portuguese researchers were confronted with the need to answer locally relevant cancer problems, like gastric cancer, and to simultaneously integrate the international scientific community, whose research priorities often center on cancer problems and types of cancers afflicting central countries. Portuguese researchers effectively argued for the

\footnotetext{
${ }^{10}$ We are here considering the top 20 journals excluding meeting abstracts.

11 Lewison and Paraje (2004) calculated the research level of biomedical journals between 1980 and 2014 , attributing to each journal a numerical value on a continuum ranging from 1 (corresponding to the clinical observation pole), to 4 (corresponding to the basic research pole). Their classification captures changes over time in the research level of journals. In between the two poles, the authors consider the translational levels "clinical mix" (closer to the clinical pole) and "clinical investigation" (closer to the basic pole).

$1212 \%$ of the publications in the top twenty journals are basic research and $10 \%$ clinical mix research.

$1321 \%$ of the publications in the top twenty cited journals are clinical investigation and $11 \%$ clinical mix research.
} 


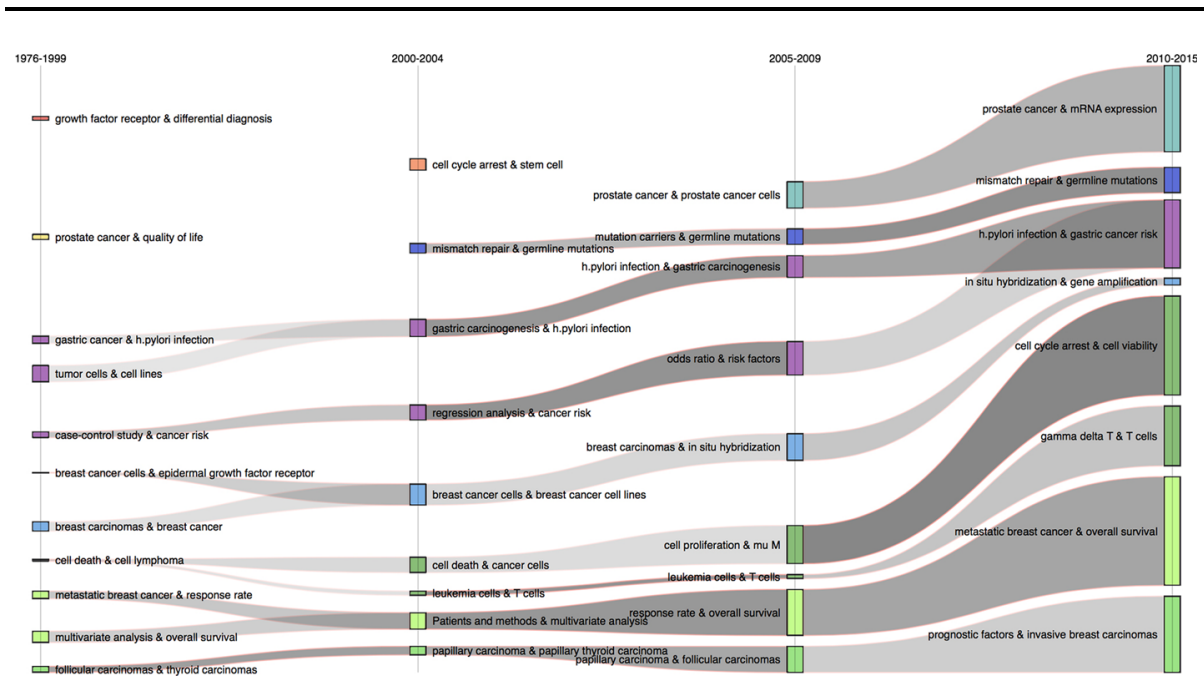

Fig. 8 Semantic network over time. The wider tubes represent the clusters with most frequent terms. Darker tubes represent clusters sharing most terms in consecutive time periods. This figure presents the most significant pairs of terms in each cluster, please see online resource 5 to see all the elements of each cluster

relevance of gastric cancer research by presenting it as an opportunity to establish important molecular findings, molecular biology having by then become a privileged approach to cancer etiology. Portuguese researchers thus successfully articulated local needs with international priorities. Another example concerns cancer epidemiology. While several cancer clusters include terms that refer to epidemiologic approaches (e.g. survival, hazard ratio), cancer epidemiology only explicitly appears on our map in connection to cervical cancer, pointing to the fact that Portugal does not have a strong cancer epidemiology field with its own dynamics. Even more worrying is the fact that public health research clearly appears to be lagging behind. Given the burden of cancer in the country, one would expect it to become a major concern for future cancer research at the national level.

The limited funding for cancer research in Portugal partly explains why clusters centered on new technological platforms such as microarrays and new generation sequencing, are absent from the semantic network. These new technologies, however, are present in the organ-based clusters, and frequently correspond to collaborations between Portuguese teams with expertise in certain cancer types and international teams with access to the novel technical tools. Such a pattern can be contrasted with developments in countries with a more intensive investment in science, where in recent years technological developments have triggered major surges in oncology research.

To investigate the evolution of research topics, we built semantic maps for four different periods (1976-1999, 2000-2004, 2005-2009, 2010-2015) and represented the changing semantic structure using a river network (Fig. 8) that captures continuities and discontinuities in thematic domains (Cortext 2016). 


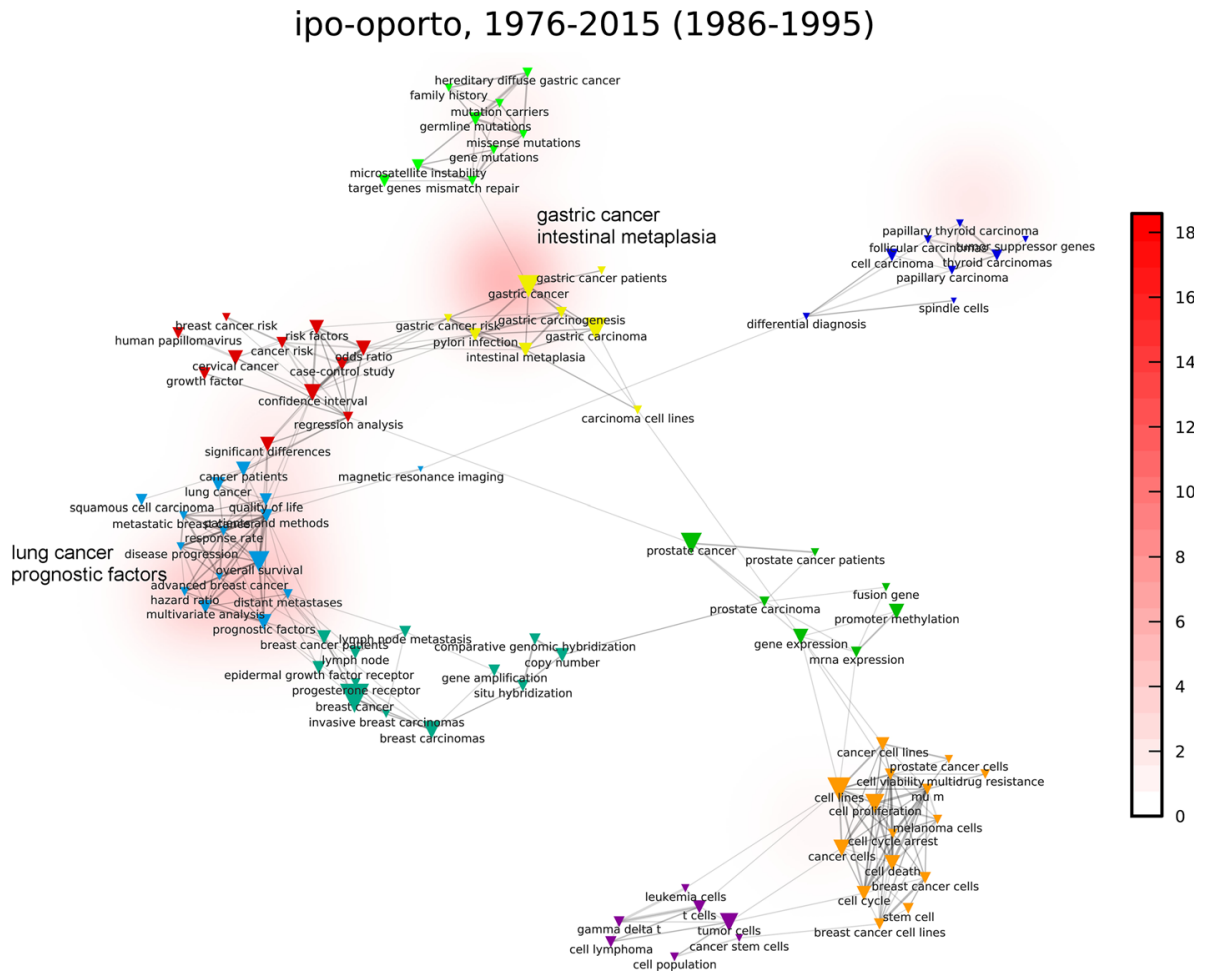

Fig. 9 Thematic specialization of IPO Porto (1986-1995)

While the temporal evolution of clusters - their emergence, convergence, separation or termination - could be related to a number of different reasons that need to be explored in future work, we can suggest a few initial interpretations. The cluster named "cell cycle arrest and cell viability" during the most recent period is the largest and more robust cluster on the river map, and shows a continuous growth along time. Its evolution points to a generalization process, whereby the cluster, which focuses on the study of cancer cells and different aspects of their "cycle" such as proliferation or death, initially did so in connection to lymphoma, and gradually englobed breast cancer, melanoma and prostate cancer.

The cluster "Pylori infection and gastric cancer risk" shows the merging of several subgroups during the time frame covered by the map. These subgroups include terms that 


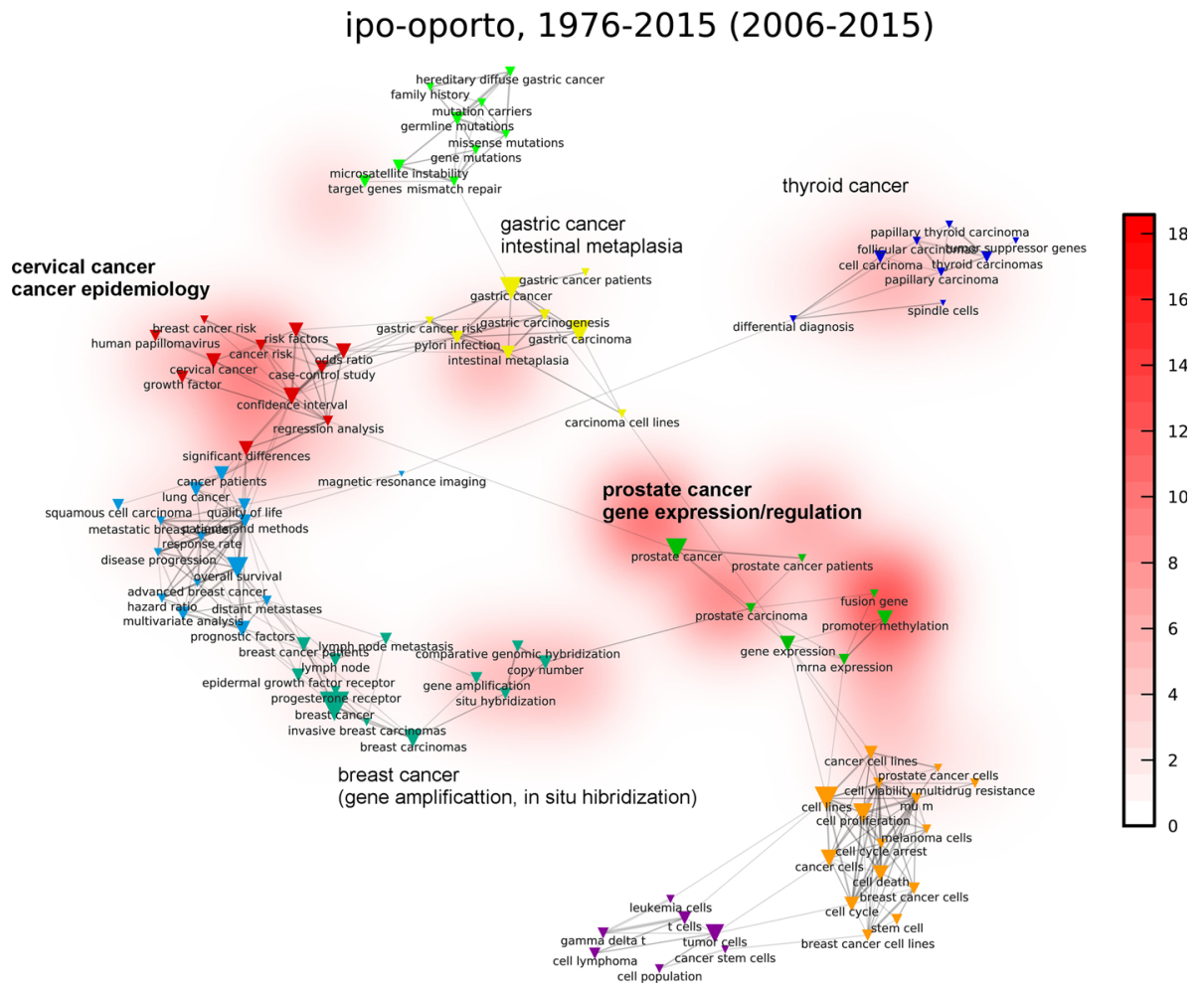

Fig. 10 Thematic specialization of IPO Porto (2006-2015)

reflect different centers of attention, from epidemiology and risk assessment, to more intensive cell biology studies, all converging into a common model of gastric carcinogenesis linked to H. Pylori infection.

The cluster "Prostate cancer and prostate cancer cells" is the most recent in the semantic network. It started in 2005-2009 and increased its relevance since then.

The cluster "In situ hybridization and gene amplification" shows merging and then decay. It lost relevance over time. In situ hybridization is a method generally used to analyze gene amplification, a genetic alteration very frequent in breast cancer. One possible explanation for the shrinking of this cluster is that in situ hybridization became a routine procedure performed mostly in breast cancer, therefore losing its relevance as a distinct research cluster. 


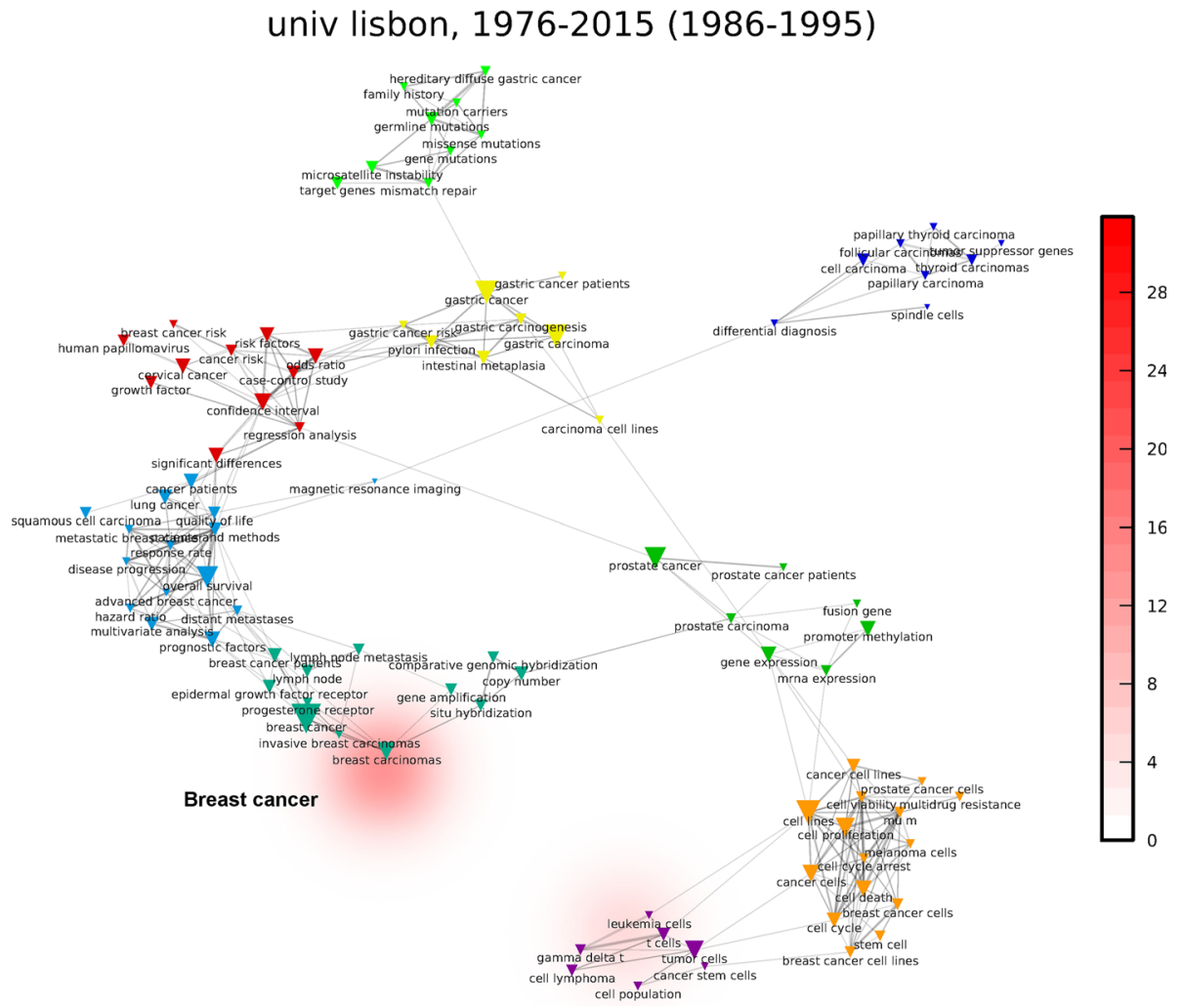

Fig. 11 Thematic specialization of University of Lisbon (1986-1995)

\section{Institutional thematic specialization}

Institutions were not all equally involved in the structuring of the semantic network. Moreover, the topics they studied and their degree of specialization changed over time. To illustrate this dynamics, we built heat maps for the top-20 research institutions, that display 


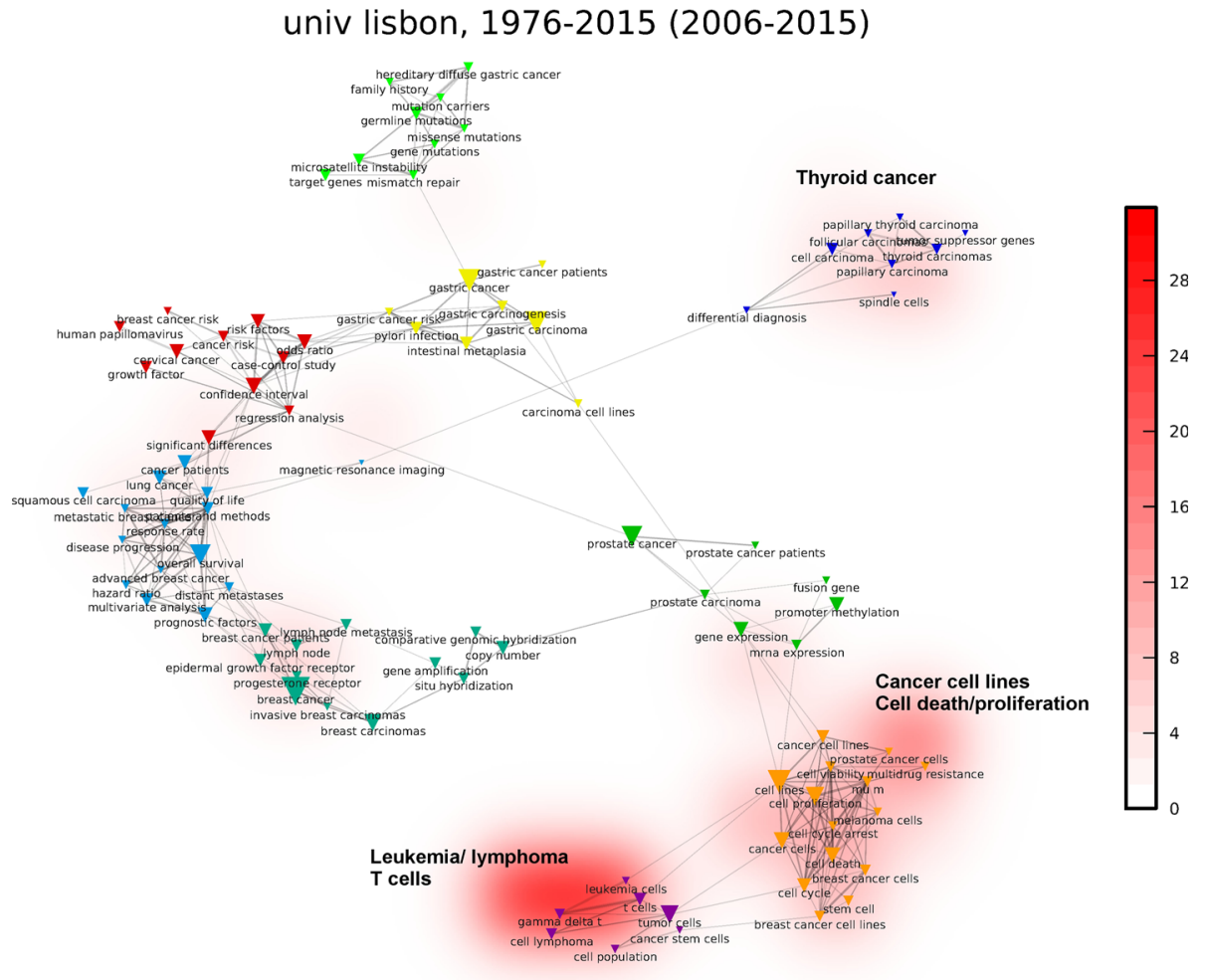

Fig. 12 Thematic specialization of University of Lisbon (2006-2015)

the degree to which each institution has contributed to a specific thematic domain. ${ }^{14}$ About half of these institutions focused their work from the outset on several themes and/or enlarged their thematic reach over time. Five institutions specialized in one topic, in particular leukemia cells/T-cells, and cancer cell lines/cell death/proliferation. The remaining institutions work in two or three themes.

While for obvious reasons we cannot discuss each of the twenty institutions, we selected three institutions - a hospital-based institution (IPO-Porto), a university (University of Lisbon), and an associate laboratory (CNC)—for the purpose of demonstration. While IPO

\footnotetext{
14 The more intense the red color of the spots the more an institution has focused on that theme. Each set of heat maps for one institution presents its own scale, calculated according to the total number of publications of that institution and the maximum specialization level it presents. We have defined ten-year periods for the heat maps so we can see what were the main themes each institution focused on over time.
} 


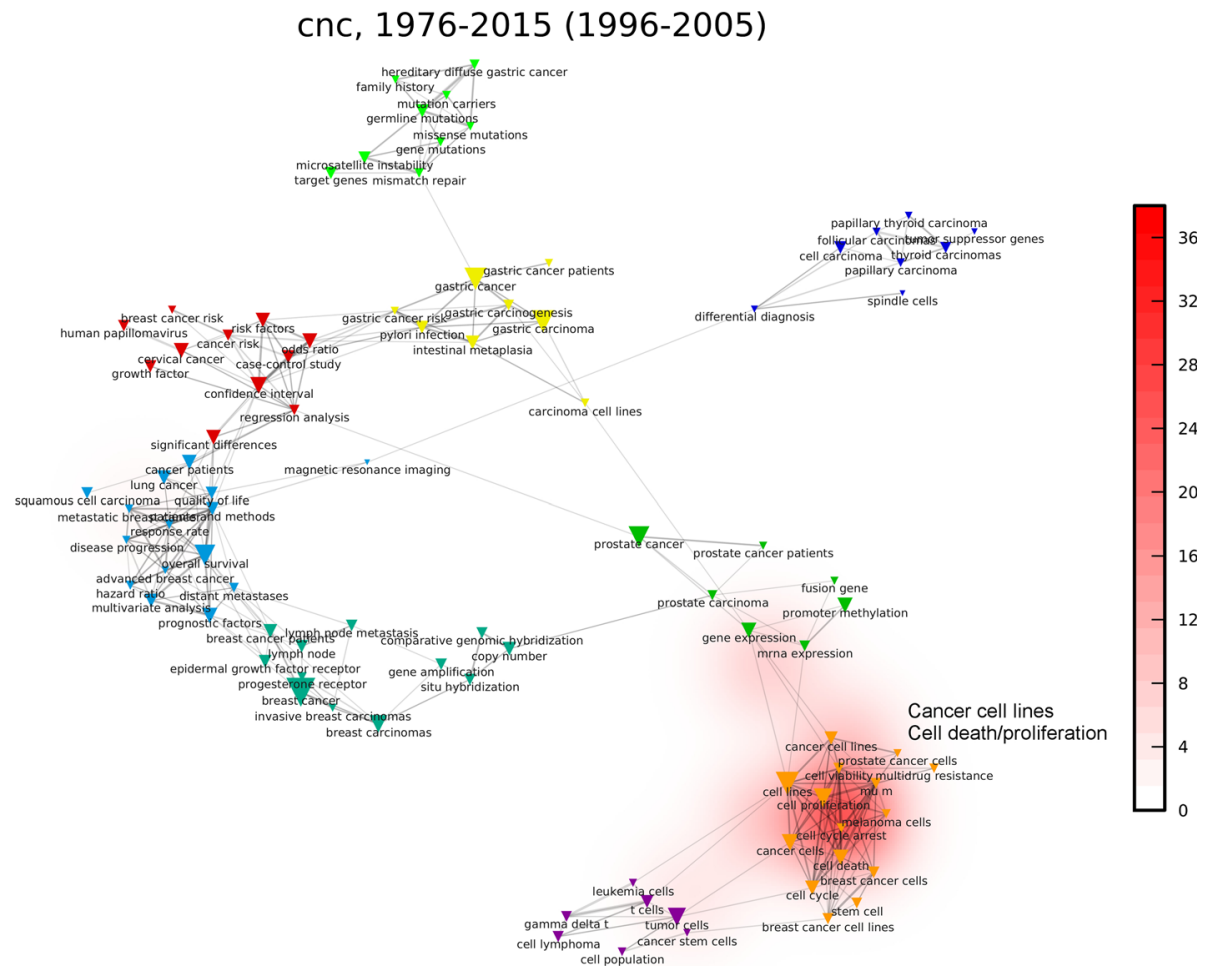

Fig. 13 Thematic specialization of CNC (1996-2005)

Porto worked from the outset on several themes and continued to do so in subsequent periods, the University of Lisbon began by privileging one topic and subsequently enlarged its focus to two main topics. In contrast, CNC strongly specialized on one topic during the entire period. The different patterns deserve further study but may be accounted by reasons as simple as the number of researchers involved (more researchers, higher diversity), institutional strategies toward specialization or thematic dispersion related to the return of Portuguese scientists' diaspora (Figs. 9, 10, 11, 12, 13, 14). 


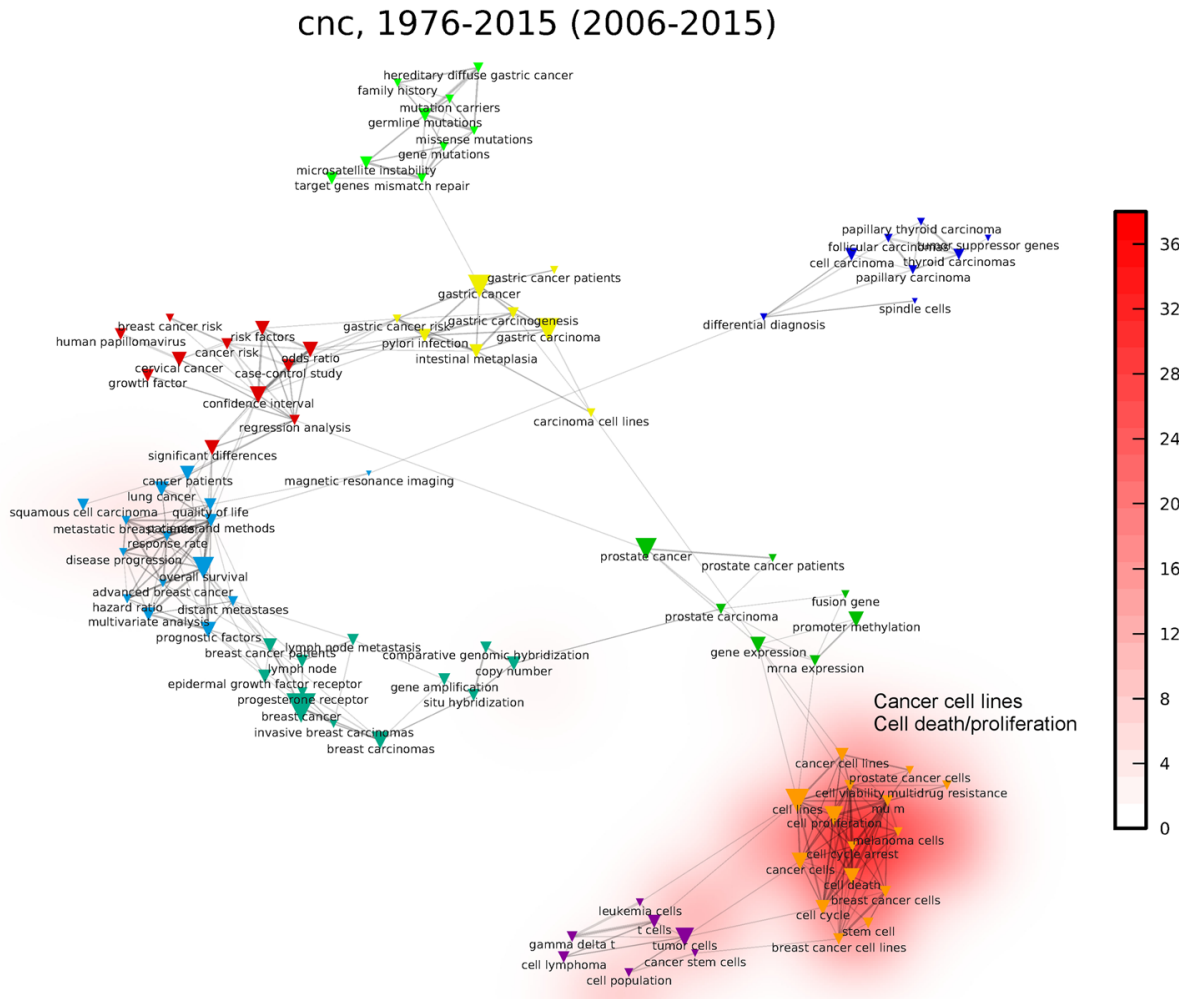

Fig. 14 Thematic specialization of CNC (2006-2015)

\section{Final remarks}

We present a portrait of oncology research in Portugal from 1976 to 2015, focusing on several aspects that can be derived from the investigation of publication patterns and the network analysis of institutional collaborations and thematic domains. In particular, we have shown that the dynamics of Portuguese oncology research was closely related to the developments in the policies for science and technology in the country. The consolidation of a science and technology policy from the end of the 80s and especially in the 90s of the twentieth century, together with Portugal's admission to the European Union, are in line with the growth in the number of publications, and also with the patterns of international collaborations, with european institutions having a fundamental role in the beginnings of Portuguese oncology research and USA and Brazil gaining more prominence recently. The collaboration networks revealed a strong connection between the laboratory and the clinic with a balanced number of non-clinical institutions (universities, research centers and associate laboratories) and clinical institutions conducting research and consistently working together. The thematic networks and their development showed a predominance of organcentered research, reflecting the strong links of Portuguese oncology research to pathology and clinical work. Researchers deal with short domestic resources for research, a pressing 
evaluation of their work's relevance and their geopolitical position through a continuous negotiation between the country's needs and profile and the priorities set by central countries which determine funding and results' reception in the international scientific community. Interestingly, a relevant translational production is the outcome of these processes.

We are of course aware of the fact that a scientometric and network analysis approach can only point to issues and questions, rather than providing definitive answers. More specific insights can only be derived by more detailed investigations combining semiquantitative approaches as featured in this paper, with more detailed qualitative investigations.

Acknowledgements Oriana Rainho Brás would like to thank Diogo Cordeiro, Rita Rainho, and Tiago Ribeiro for their support.

Funding This research was funded by Fundação Calouste Gulbenkian, Bristol Myers Squibb and ASPICPortuguese Association for Cancer Research.

\section{References}

Cambrosio, A., Keating, P., Mercier, S., Lewison, G., \& Mogoutov, A. (2006). Mapping the emergence and development of translational cancer research. European Journal of Cancer, 42, 3140-3148.

CorTexT (2012). CorTexT digital plateform: Context, stakes and objectives. http://www.cortext.net/aboutus/cortext-digital-plateform-context-stakes-and-objectives.html. Accessed June 32016.

CorText (2016). CorTexT manager documentation. analysing data. Dynamical settings. https://docs.cortext. net/analysis-mapping-heterogeneous-networks/mapping-dynamical-analysis-options/. Accessed Sept 212016.

Costa, R. M. P. (2010). Discurso médico, saúde pública e estratégias políticas para 'Uma questão palpitante do tempo actual': A emergência da luta contra o cancro em Portugal (1904-1923). Revista da Faculdade de Letras: História, 11(1), 135-164.

Costa, R. M. P. (2012a). Between parasitic theory and experimental oncology: A proposal for systematizing oncological science in Portugal, 1889-1945. História, Ciências, Saúde-Manguinhos, 19(2), 409-430.

Costa, R. M. P. (2012b). Instituto Português de Oncologia: organização e dinâmica assistencial (1928-1958). Estudos do Século XX, 12, 311-333.

Eckhouse, S., Castanas, E., Chieco-Bianchi, L., Cinca, S., Meunier, F., Moulton, B., et al. (2005). European cancer research funding survey. ECRMFORUM.

Eckhouse, S., \& Sullivan, R. (2006). A survey of public funding of cancer research in the European union. PLoS Medicine, 3(7), 0994-0997.

Gonçalves, M. E. (1996). The politics of science policy in the periphery of Europe: The case of Portugal. Science Technology \& Society, 1(2), 291-310.

Grassano, N., Rotolo, D., Hutton, J., Lang, F., Hopkins, M. (2016). Funding data from publication acknowledgments: Coverage, users and limitations. SPRU Working Paper Series. SWPS April 08 2016. University of Sussex. http://www.cla.org.pt/oquesao.shtml. Accessed June 32016.

Heitor, M., Horta, H., \& Mendonça, J. (2014). Developing human capital and research capacity: Science policies promoting brain gain. Technological Forecasting and Social Change, 82, 6-22.

IPO (2016). História do IPO. Criação do Instituto. Serviço Nacional de Saúde. http://www.ipolisboa.minsaude.pt/Default. aspx ?Tag=DOSSIER $\&$ DossierId $=6 \&$ ContentId=876\&Id=00000000-0000-00000000-000000000000\#content. Acessed Jan 92017.

Jones, D. S., Cambrosio, A., \& Mogoutov, A. (2011). Detection and characterization of translational research in cancer and cardiovascular medicine. Journal of Translational Medicine, 9, 57.

Keating, P., \& Cambrosio, A. (2012). Cancer on trial: Oncology as a new style of practice. Chicago: The University of Chicago Press.

Lewison, G., \& Paraje, G. (2004). The classification of biomedical journals by research level. Scientometrics, 60(2), 145-157.

Nunes, J. A. (2001). Laboratórios, escalas e mediações na investigação biomédica. A oncobiologia entre o global e o local. In J. A. Nunes \& M. E. Gonçalves (Eds.), Enteados de Galileu? A semiperiferia no sistema mundial de ciência (pp. 33-75). Porto: Edições Afrontamento. 
Pordata (2016). Scientific publications: Total and by scientific area-Global count-Portugal. http://www. pordata.pt/en/Portugal/Scientific+publications+total+and+by+scientific+area+\%e $2 \% 80 \%$ 93+Global+count-1137. Accessed Feb 92017.

Ràfols, I., \& Molas-Gallart, J. (2016). A call for inclusive indicators that explore research activities in "peripheral" topics and developing countries. The Impact blog. London School of Economics and Political Science. http://blogs.lse.ac.uk/impactofsocialsciences/2016/03/01/a-call-for-inclusiveindicators-we-need-better-metrics-to-explore-research-activities-in-peripheral-topics-and-developingcountries/. Accessed June 22016.

Raposo, H. (2004). A luta contra o cancro em Portugal. Análise do processo de institucionalização do Instituto Português de Oncologia. In Fórum Sociológico (no. 11/12, 2nd séries: pp. 177-203).

Simões, J., Augusto, G. F., Fronteira, I., \& Hernández-Quevedo, C. (2017). Portugal: Health system in review. Health Systems in Transition, 19(2), 1-184. 